\title{
Osteogenesis Imperfecta in Two Finnish Lapphund Puppies
}

\author{
Ming Yi Tse (D) \\ lan R Porter (iD) ${ }^{2}$ \\ Elena Demeter ${ }^{3}$ \\ Erica Behling-Kelly ${ }^{4}$ \\ Joseph J Wakshlag ${ }^{2}$ \\ Andrew D Miller ${ }^{3}$
}

'City University of Hong Kong, Jockey Club College of Veterinary Medicine and Life Sciences, Hong Kong, 999077, People's Republic of China; ${ }^{2}$ Cornell University College of Veterinary Medicine, Department of Clinical Sciences, Ithaca, NY, I4850, USA;

${ }^{3}$ Cornell University College of Veterinary Medicine, Department of Biomedical

Sciences, Section of Anatomic Pathology, Ithaca, NY, I 4853, USA; ${ }^{4}$ Cornell

University College of Veterinary Medicine, Department of Population Medicine, Ithaca, NY, I4853, USA
Correspondence: Joseph J Wakshlag Department of Clinical Sciences, Cornell University College of Veterinary Medicine, Clinical Sciences C3-536, Ithaca, NY, I 4853, USA

Tel + I 607253-4389

Email Jw37@cornell.edu

\begin{abstract}
Two 8-week-old Finnish Lapphund dogs presented with pain on manipulation, abnormal long bone conformation, retrognathism, and stunted growth compared to their litter mates. Multiple long bone fractures were evident on radiographs. Clinical pathology showed an atypically normal serum alkaline phosphatase activity for dogs this age. Due to poor quality of life, the dogs were humanely euthanized and subjected to a complete necropsy. On necropsy, all bones were soft and easily broken. Histologic examination revealed that the secondary spongiosa was diminished with abnormal bony trabeculae embedded in abundant loose vascular stroma. No Haversian canals were observed and the cortices contained abundant woven bone separated by fibrovascular tissue consistent with the diagnosis of osteogenesis imperfecta (OI). Inbreeding of the sire and female offspring led to a suspicion of recessive inheritance and the particular genetic collagen disorder remains to be identified in this breed.
\end{abstract}

Keywords: osteogensis imperfecta; OI, dog, histopathology

\section{Introduction}

Osteogenesis imperfecta (OI), also known as brittle bone disease, is a heritable genetic collagen disorder that leads to clinical signs including skeletal fragility, skeletal deformity, joint laxity, and scoliosis ${ }^{1}$ This disorder is associated with defective connective tissues and bone formation, and can also affect extraskeletal tissues and organs. ${ }^{2-4}$ Extraskeletal presentations include hypercalciuria, blue/grey sclera, hearing loss, dentinogenesis imperfecta, and aortic root dilation. ${ }^{5-8}$ In milder cases, musculoskeletal clinical signs such as joint pain, fractures, back pain, and tendon ruptures are common in humans. ${ }^{1,5-8}$ Other OI manifestations include neurologic conditions such as macrocephaly, hydrocephalus, and basilar invagination. $^{9-11}$ In human medicine, OI is most often characterized by bone fragility and phenotypic differentiation including blue/greyish discoloration of the sclera and dentinogenesis imperfecta are considered when classifying type I to IV OI. $^{12,13}$

Given the great variety of pathological conditions that can interfere with the physiological development in the animal skeleton, researchers in early 1970 established a nosology and classification system of skeletal disorders in humans to make definitive diagnosis and prognosis possible. ${ }^{14}$ As of 2019 , the system had a collection of 461 genetic disorders of the skeleton classified, involving 437 genes in 42 groups. $^{15}$ OI belongs to group 25 of this classification system, together with other bone density disorders. In humans, the majority (more than 90\%) of OI cases are the result of 
autosomal dominant mutations in genes that encode type I collagen: COL1A1 (collagen type I alpha 1 chain) and COL1A2 (collagen type I alpha 2 chain). ${ }^{16}$

In animals, OI has been reported in domestic species such as dogs, cats, cattle, and sheep as well as captive tigers. ${ }^{17-28}$ $\mathrm{OI}$ is uncommon in veterinary medicine with a majority of cases being diagnosed primarily through histopathologic examination with more current reports delving into genetic causes. Current, animal model and naturally occurring diseases involved in the diagnosis of OI are included in the University of Sydney Online Mendelian Inherited Database as a reference for all reported incidences with identified genetic causes (https://www.omia.org/home/). In published reports of dogs, OI is described in the Dachshund, Chow Chow, Golden Retriever, Beagle, Collie, Norwegian Elkhound, Bedlington Terrier, and Lagotto Romagnolo and in one case of a mixed breed litter; with the hallmark findings being orthopedic dysfunction leading to minimal trauma or non-traumatic fractures. ${ }^{22-28}$ In some of these cases the bone pathology is limited to a single long bone, while in other cases as described in Dachshunds, Collies, and Beagles; newborn puppies develop multiple non-traumatic long bone fractures and often have delayed growth curves compared to healthy litter mates and potential hypodontia. ${ }^{22-28}$ The disorder can be autosomal dominant or recessive and genetic aberrations have been identified as the SERPINH1 mutation in the Dachshund, and the COL1A2 mutation in the Chow Chow and Lagotto Romagnolo. ${ }^{25,26,28}$

This case report describes OI in two 8-week-old male Finnish Lapphund puppies that were referred to the Cornell University Hospital for Animals with an initial complaint of abnormal radius curvus of the forelimbs, being smaller than litter mates (weights of normal litter mates could not be obtained), and displaying poor mobility. The puppies were part of a litter of six that resulted from a breeding between a sire and female offspring of that sire from a previous litter. On presentation to our clinic, radiographic confirmation of abnormal conformation and folding fractures of multiple long bones were identified. Following clinical evaluation that included a physical examination, complete blood counts, serum biochemistry, and thyroid hormone testing the puppies were humanely euthanized due to poor quality of life and submitted for necropsy and histopathology examination.

\section{Clinical Summary}

At three weeks of age the owner identified that the two aforementioned puppies were significantly smaller and less mobile than the 4 healthier litter mates (Figure 1). It was also noted by the owner that the teeth appeared to be delayed in eruption from the upper and lower arcade. According to the owner the puppies were eating well, showed normal defecation and urination patterns, and were in good body condition, although stunted in growth compared to litter mates. At that time based on limited telemedicine examination due to the coronavirus pandemic, a presumed inherited musculoskeletal or neurologic abnormality was postulated.

At 8 weeks of age the puppies were admitted to the Cornell University Hospital for Animals. Historically, the puppies continued to grow, but were smaller than litter mates with obvious limb deformities in the forelimbs and hypomobility. Puppy one weighed $1.2 \mathrm{~kg}$ on presentation, while puppy two weighed $1.6 \mathrm{~kg}$, with no significant

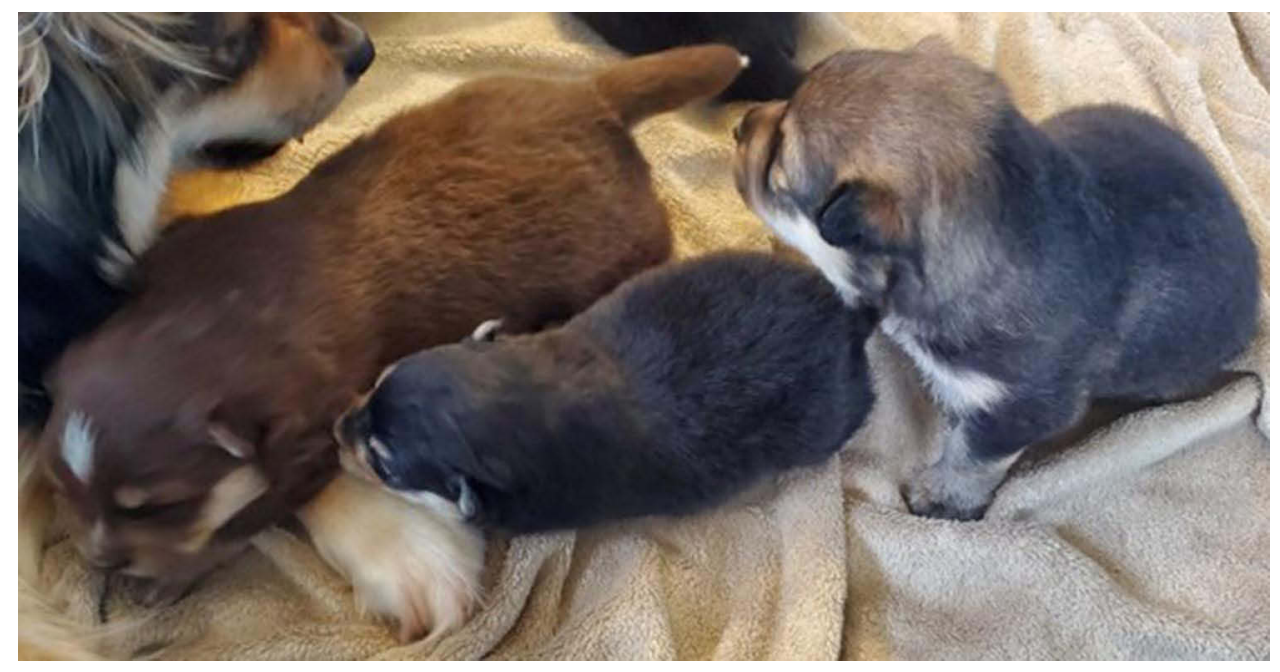

Figure I Picture showing the stunted growth of puppy one compared to litter mates at 3 weeks of age. 

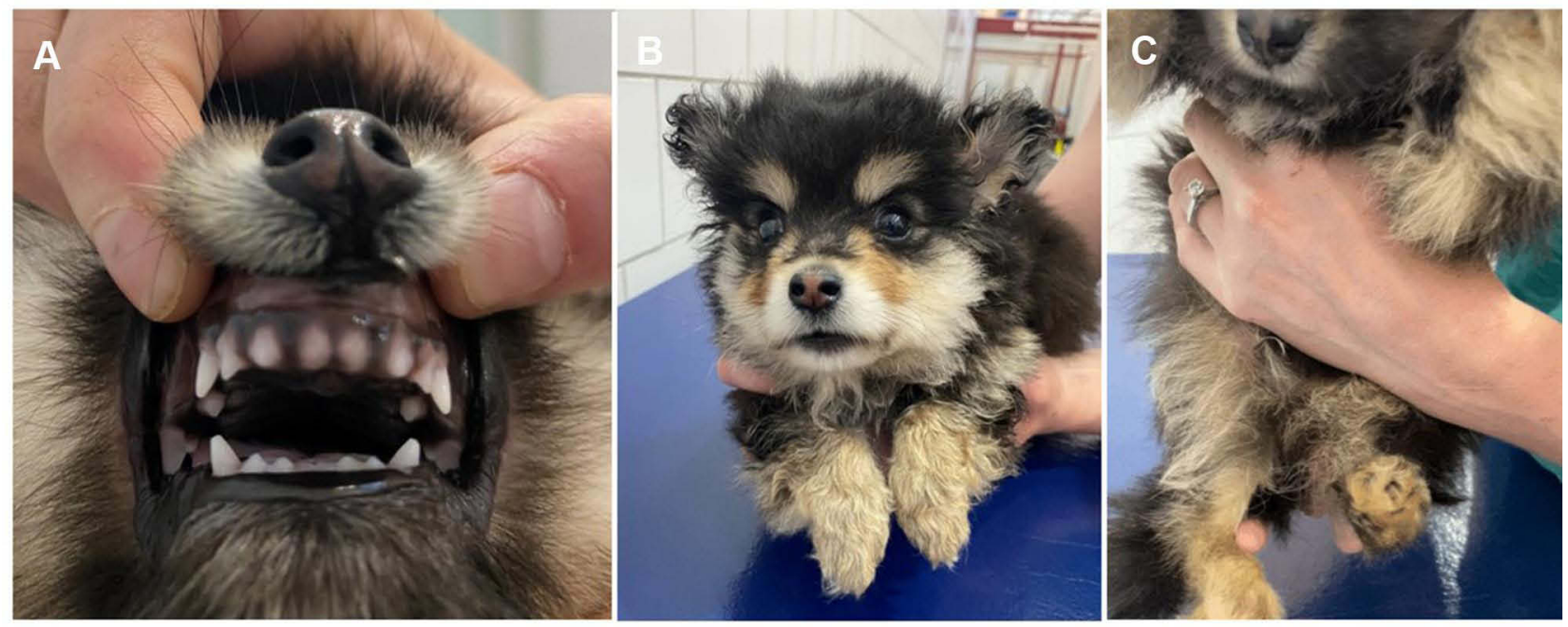

Figure 2 (A) Picture showing the normal orientation of teeth but abnormal eruption observed in upper arcade of puppy two at 8 weeks of age. (B) Picture displaying the carpal valgus orientation of puppy one at 8 weeks of age. (C) Picture displaying the varus deformity on the left hindlimb and contracture of the right hindlimb in puppy two at 8 weeks of age.

findings in their vital parameters on physical exam. During oral examination mild hypodontia and retrognathism was identified in both dogs (Figure 2A). Both puppies displayed valgus deformities of the carpus and a limited range of motion at the elbow and shoulder bilaterally (Figure 2B). There was profound muscle atrophy in the forelimbs and the hindlimbs. On hindlimb manipulation, there was pain during hip extension and knee flexion with limited range of motion, and puppy two appeared to display a varus orientation of the right hindlimb with contracture of the right hindlimb (Figure 2C). Neurologic evaluation found delayed proprioception in all limbs that was deemed to be pain related.

Both dogs were intravenously sedated using dexmedetomidine $(5 \mathrm{ug} / \mathrm{kg})$ and butorphanol $(0.2 \mathrm{mg} / \mathrm{kg})$ for radiography and computed tomography imaging. Immediately following imaging blood was collected for complete blood counts, serum biochemistry and thyroid hormone screening.

\section{Clinical Pathology Findings}

The complete blood count revealed a low red blood cell count and hemoglobin concentration, mild increase in reticulocytes, and a mild mature neutrophilia in relationship to adult reference ranges (Table 1). These findings are documented as normal variation in healthy puppies of similar age. ${ }^{29-31}$ The prototypical age-associated biochemical findings include a mild panhypoproteinemia and hyperphosphatemia. Serum alkaline phosphatase activity was within the adult reference range, and is considered an abnormal finding in young puppies since bone growth is expected to contribute to a higher serum activity of this enzyme. $^{29-31}$ Both puppies had an increased serum creatine kinase activity which can be normal in puppies of this age, ${ }^{29}$ but may also be elevated due to presumed progressive muscle damage. Puppy one displayed an increased serum lactate dehydrogenase activity (Table 2).

Table I Complete Blood Count for Puppy I and Puppy 2 at 8 Weeks of Age

\begin{tabular}{|c|c|c|c|}
\hline Complete Blood Count & Puppy I & Puppy 2 & Ref. Range \\
\hline Hematocrit (\%) & 34 & 34 & $41-58$ \\
\hline Hemoglobin (g/dL) & 10.6 & 10.2 & |4.|-20.| \\
\hline Red Blood Cells (mil/uL) & 4.6 & 4.9 & $5.7-8.5$ \\
\hline Mean Corpuscle Volume (fL) & 74 & 69 & $64-76$ \\
\hline Mean Corpuscle Hemoglobin (pg) & 23 & 21 & $21-26$ \\
\hline $\begin{array}{l}\text { Mean Corpuscle Hemoglobin conc. } \\
(\mathrm{g} / \mathrm{dL})\end{array}$ & 31 & 30 & $33-36$ \\
\hline Red Cell Distribution and Width (\%) & 12.6 & 13.7 & $10.6-14.3$ \\
\hline Reticulocyte Count (\%) & 2.2 & 1.6 & $0.2-1.5$ \\
\hline $\begin{array}{l}\text { Absolute Reticulocyte Count } \\
\text { (thou/uL) }\end{array}$ & 102 & 77.3 & $11.0-92.0$ \\
\hline $\begin{array}{l}\text { Nucleated Red Blood Cells (/100 } \\
\text { WBC) }\end{array}$ & 0 & 0 & $0-1$ \\
\hline White Blood Cells (thou/uL) & 12.7 & 14.7 & $5.7-14.2$ \\
\hline Segmented Neutrophils (thou/uL) & 10.4 & 12.2 & $2.7-9.4$ \\
\hline Lymphocytes (thou/uL) & 1.2 & 1.2 & $0.9-4.7$ \\
\hline Monocytes (thou/uL) & 0.9 & 0.7 & $0.1-1.3$ \\
\hline Eosinophils (thou/uL) & 0.3 & 0.1 & $0.1-2.1$ \\
\hline Basophils (thou/uL) & 0 & 0 & $0.0-0.1$ \\
\hline Platelets (thou/uL) & 616 & 690 & $186-545$ \\
\hline Mean Platelet Volume (fL) & 9.8 & $1 \mathrm{I} . \mathrm{I}$ & $8.4-14.1$ \\
\hline
\end{tabular}

Note: Bolded values are outside of the reference range. 
Table 2 Serum Biochemistry, Total Serum Thyroid Hormone (Total T4) and Free Serum Thyroid Hormone (Free T4) Results for Puppy I and Puppy 2 at 8 Weeks of Age.

\begin{tabular}{|c|c|c|c|}
\hline Serum Biochemistry & Puppy I & Puppy 2 & $\begin{array}{l}\text { Ref. } \\
\text { Range }\end{array}$ \\
\hline Sodium (mEq/L) & $|4|$ & 145 & $143-150$ \\
\hline Potassium (mEq/L) & 5.8 & 5.1 & $4.1-5.4$ \\
\hline Chloride (mEq/L) & 108 & 108 & $106-114$ \\
\hline Bicarbonate (mEq/L) & 23 & 24 & $14-24$ \\
\hline Anion Gap & 17 & 17 & $16-27$ \\
\hline Urea Nitrogen $(\mathrm{mg} / \mathrm{dL})$ & 12 & 9 & $9-26$ \\
\hline Creatinine (mg/dL) & 0.2 & 0.2 & $0.6-1.4$ \\
\hline Calcium (mg/dL) & 10.3 & 10.7 & $9.4-11.1$ \\
\hline Phosphate (mg/dL) & 5.7 & 6.5 & $2.7-5.4$ \\
\hline Magnesium (mEq/L) & 1.9 & 1.9 & $1.5-2.1$ \\
\hline Total Protein $(\mathrm{g} / \mathrm{dL})$ & 3.8 & 4 & $5.5-7.2$ \\
\hline Albumin $(\mathrm{g} / \mathrm{dL})$ & 1.5 & 2.7 & $3.2-4.1$ \\
\hline Globulin (g/dL) & 1.5 & 1.3 & $1.9-3.7$ \\
\hline Glucose (mg/dL) & 90 & 105 & $68-104$ \\
\hline Alanine Aminotransferase (U/L) & 17 & 28 & $17-95$ \\
\hline $\begin{array}{l}\text { Aspartate Aminotransferase } \\
(\mathrm{U} / \mathrm{L})\end{array}$ & 34 & 37 & $18-56$ \\
\hline Alkaline Phosphatase (U/L) & 86 & 88 & $7-115$ \\
\hline $\begin{array}{l}\text { Gamma Glutamyltransferase } \\
(\mathrm{U} / \mathrm{L})\end{array}$ & 3 & 4 & $0-8$ \\
\hline Total Bilirubin (mg/dL) & 0 & 0 & $0.0-0.2$ \\
\hline Direct Bilirubin (mg/dL) & 0 & 0 & $0.0-0.1$ \\
\hline Indirect Bilirubin (mg/dL) & 0 & 0 & $0.0-0.1$ \\
\hline Amylase (U/L) & 405 & 332 & $322-1310$ \\
\hline Lipase (U/L) & 224 & 81 & $15-228$ \\
\hline Cholesterol (mg/dL) & 244 & 202 & $136-392$ \\
\hline Creatine Kinase (U/L) & 592 & 751 & $64-314$ \\
\hline Lactate Dehydrogenase (U/L) & 412 & 369 & $24-388$ \\
\hline Iron (ug/dL) & 185 & 132 & $97-263$ \\
\hline Total T4 (ug/dL) & 2.1 & 2.4 & $1.5-3.0$ \\
\hline Free T4 (ng/dL) & 1.5 & I.I & $0.7-2.5$ \\
\hline
\end{tabular}

Note: Bolded values are outside of the reference range.

\section{Radiographic Findings}

Diffusely there was generalized decrease in bone opacity (diffuse osteopenia) throughout the skeleton of both puppies identified by the board certified radiologist (IP). The cortices of all long bones were severely diminished and multiple "folding" fractures were present with minimal callus formation (Figure 3A-C). Differential diagnosis based on the radiographs included both skeletal dysplasia and metabolic bone disease. When considered with the clinical history, a skeletal dysplasia such as OI was considered most likely. Due to the multiple fractures and skeletal deformities associated with the poor prognosis the owner elected humane euthanasia. The dogs were cared for under the best practices of veterinary care and within the guidelines for the Cornell University Hospital for Animals. The owner signed informed consent regarding the euthanasia and provided consent for pathologic examination of tissue to confirm the presumptive diagnosis of OI with permission for presentation and/or publication. As these were not research animals, and were client owned, these dogs were exempt from any institutional animal use and care committee approval oversight.

\section{Pathologic Findings}

At necropsy, upon manipulation, all examined bones were brittle and easily fractured when applying minimal force. Light microscopy evaluation of representative sections of the mandible, femur, ribs, humerus, scapula, and entire skull at the mid-nasal cavity level were performed for both puppies, in addition to all major organs.

In all sections of femur, humerus, ribs examined the secondary spongiosa was lacking with the remaining bony trabeculae having frequent reversal lines, rare osteocytes, and lined by a layer of small osteoblasts that sometimes contained a cytoplasmic vacuole and frequent osteoclasts. Loose fibrovascular stroma was present between the trabeculae. In all sections of bone no Haversian canals were noted in any of the cortices. The cortices had thin, irregular, woven bone separated by fibrovascular tissue (Figure 4) and the periosteum was absent (Figures 4 and 5). Examination of tooth morphology was normal with subjective thinning of the dentin layer (Figure 5).

\section{Discussion}

In this study, we clinically and pathologically diagnosed two 8-weeks-old Finnish Lapphund puppies of the same litter with OI. These two puppies started showing OI clinical signs within the first 3 weeks of life, similar to the OI cases described in Golden Retrievers, Collies, Beagles, Bedlington Terrier, Dachshunds and Lagotto Romagnolos. ${ }^{17,22-25,27,29,32,33}$ On clinical presentation, the puppies had valgus orientation of the carpus and one also had varus orientation on the right hindlimb. There was limited range of motion on manipulation and contracture of the limbs, a finding commonly observed in human cases; however, similar perinatal limb deformities can also be associated with soft tissue or ligamentous laxity. ${ }^{34}$ Joint range of motion differs in various manifestations of OI, with most human cases presenting with hypomobility as observed in OI type III patients, with hypermobility observed in OI type $\mathrm{I}^{35}$ The finding of 

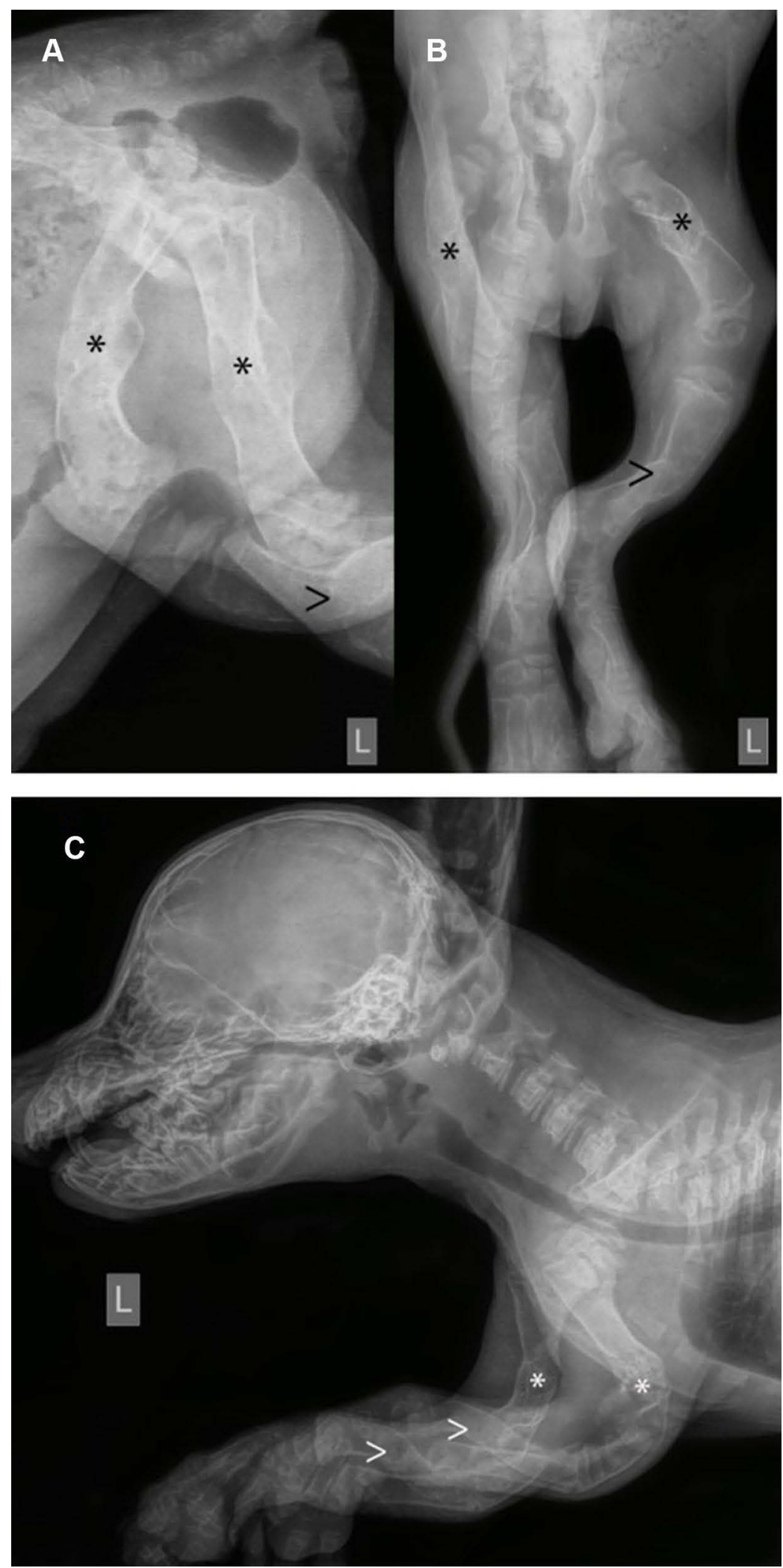

Figure 3 (A and B) Fractures are present in both the left and right femur $(*)$, the left tibia (folding fracture), questionably the right tibia (>) of puppy two. (C) Folding fractures are present in both the left and right humerus $(*)$ and radius $(>)$, and deform the shape of the limbs. Note the severe diffuse osteopenia, most severe in the long bones where there is severe cortical thinning, and in the facial bones of puppy five. 


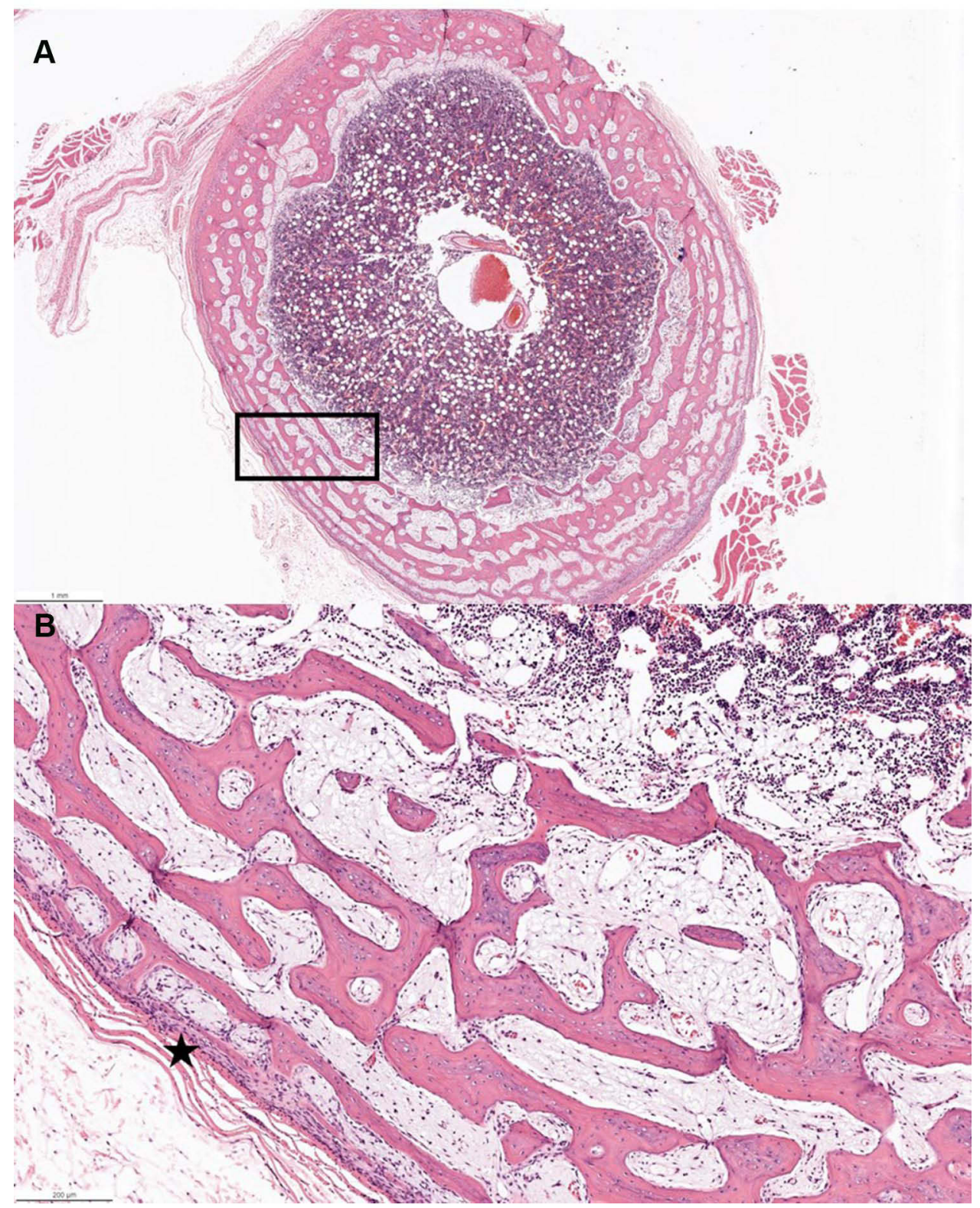

Figure 4 Femur hematoxylin and eosin staining. (A) Transverse section showing marked cortical thinning with abrupt transition from bone to muscle and subjectively hypercellular bone marrow with a black rectangle to indicate where panel B is examined at higher power (B) Higher magnification of rectangular area showing inapparent periosteum and markedly thin cortex $(*)$.

profound muscle atrophy in all four extremities in both puppies has also been observed in children. ${ }^{36}$ In addition, OI in children has also been associated with altered structural and mechanical properties of deformed tendons and ligaments. ${ }^{36}$ Although we could elicit a pain response as reported in other juvenile forms of the disease, pain responses appear to be variable and may be related to the extent of the pathological fractures depending on the case. $^{17,37}$

In addition to the pathological fractures evident on radiographs, the puppies in this report had abnormal bone histopathology. Evident osteopenia with minimal to absent cortices which lacked Haversian canals and displayed areas of dense fibrovascular stroma, which is typical of this disorder. In addition, there was delayed dentition with the dentin layer being subjectively thin, similar to the OI identified in Dachshunds and other breeds. ${ }^{17,28,36-38}$ Retrognathism, identified in both puppies, is rare among canine OI case reports, but not uncommon in humans, suggesting a possible difference in presentation in Finnish Lapphund dogs. ${ }^{39,40}$ 


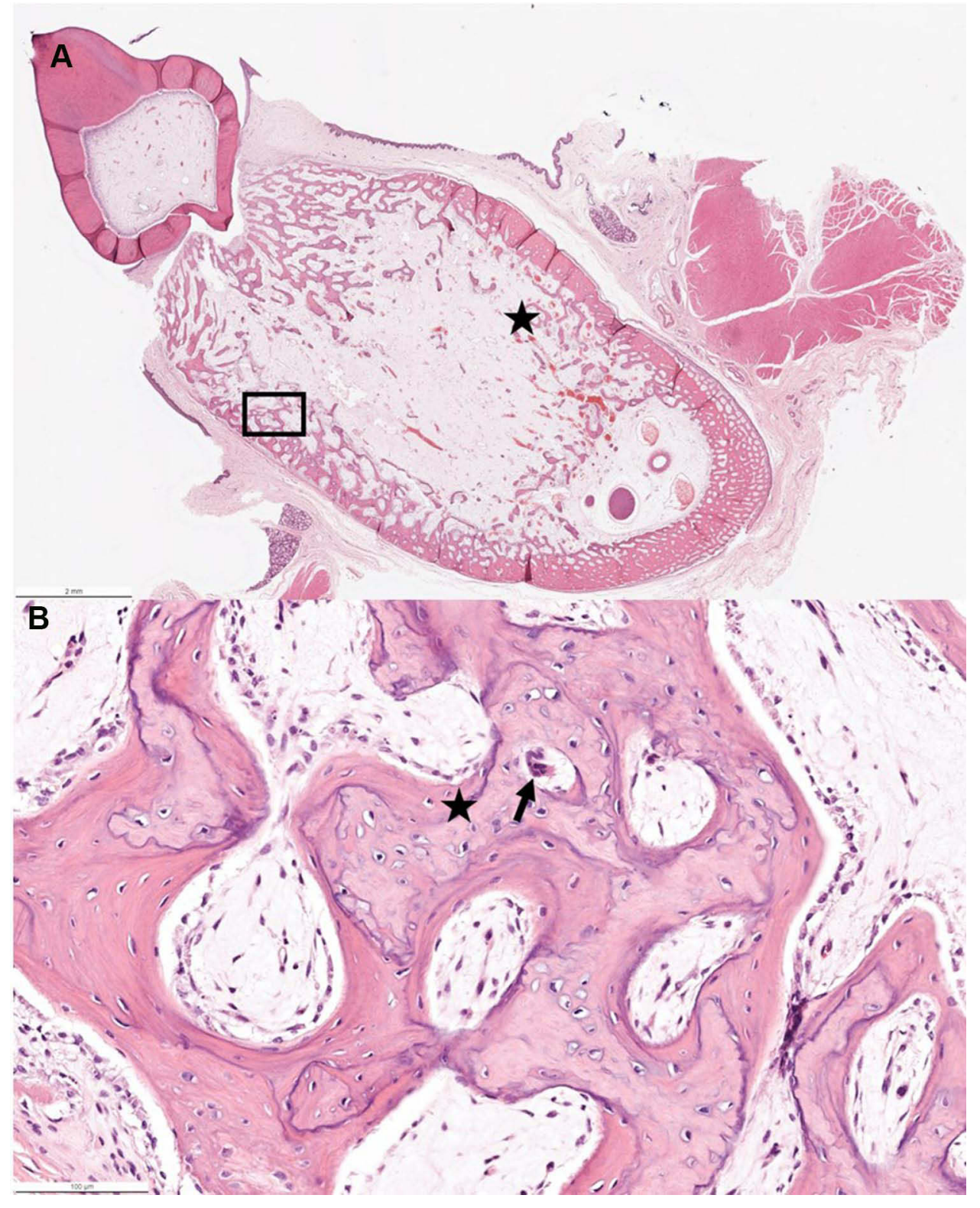

Figure 5 Mandible hematoxylin and eosin staining. (A) Traverse section revealing diminished dentin layer of the tooth and marked thinning of cortical bone with paucity of bony trabeculae $(*)$ with a black rectangle to indicate where panel B is examined at higher power (B) Higher magnification of rectangular area showing irregular bone with reversal lines $\left({ }^{*}\right)$, lined by small osteoblasts and frequent osteoclasts (arrow).

Complete blood cell count, serum chemistry and thyroid hormone testing was performed to assess any abnormalities that might be related to this disorder, and most strikingly there was no rise in alkaline phosphatase enzyme activity typical of puppies undergoing rapid bone turnover, while serum phosphorus was elevated which is typically observed in growing dogs. ${ }^{29-31}$ Red blood cell counts and hemoglobin concentrations were low which is commonly observed in puppies due to the rapid turnover of red blood cells containing fetal hemoglobin isoforms to adult isoforms leading to a normal physiological anemia. ${ }^{29}$
Other potential abnormalities in both puppies were decreases in albumin concentration and rises in creatine kinase activity. Prior literature suggests total protein can be low in puppies of this age, so the finding of low albumin may be an age-related physiological change; however, it is not well documented, except for Labradors and Schnauzers who show gradual increases from 8-26 weeks of age. ${ }^{31}$ The finding of elevated serum creatine kinase activity is likely to be an age-related finding; however, progressive muscle damage associated with the chronic pathological fractures and prolonged recumbency may 
also be contributing to this elevation. One puppy had an elevated lactate dehydrogenase as a marker of anoxic or inflamed tissue. The same puppy showed a mild elevation in neutrophils suggestive of systemic inflammation, which could be related to the mild elevation in lactate dehydrogenase.

The parents of the puppies were healthy reproducing adults. The pedigree of the puppies was consistent with a monogenic autosomal recessive inheritance and the ratio of the affected Finnish Lapphund puppies from the presumed carrier $\times$ carrier breeding in light of the father to daughter breeding in this particular case. However, given the small number of puppies within the litter, other modes of inheritance cannot be ruled out. OI in dogs is reported to be caused by autosomal dominant and recessive modes of inheritance with gene mutations in COL1A1 in a Golden Retriever, ${ }^{41} C O L 1 A 2$ in a beagle and a Chow Chow, ${ }^{28,29}$ and SERPINH1 in Dachshunds. ${ }^{42}$ COL1A1 and COL1A2 code for $\alpha 1$ and $\alpha 2$ collagen chains, associated with the production, folding, and maintenance of the structure and secretion of type 1 collagen. ${ }^{43}$ SERPINH1 encodes for heat shock protein 47 (HSP47), an essential collagen chaperone protein which aids in appropriate folding of collagens and stabilizes collagen triple helices. ${ }^{26}$ In both the Golden Retriever and Beagle there was no pedigree information to fully understand the COL1A1 and COL1A2 mutations identified, respectively. ${ }^{23,41}$ The SERPINH1 mutation observed in German Dachshunds, ${ }^{42}$ involved similar F1 to F2 breeding characteristics and clinical presentations are similar to the puppies in this case report suggesting this may be a fruitful area for future research. At this time we have not elucidated the potential mutations or modes of inheritance in the Finnish Lapphund.

Based on our pathologic and radiographic findings, the Finnish Lapphund is another identified breed with OI. Further genetic studies are warranted since communication with the breed group has identified other European bred dogs with OI. Clinical presentation as early as 3 weeks of age can be suggestive of OI and clinical pathology findings are typical for puppies of this age with the only abnormal finding related to bone metabolism being a normal alkaline phosphatase activity which could be a prognostic indicator for suspicion of OI. Veterinary community awareness is prudent for further investigation into the genetics of this disorder.

Author contribution: All authors made substantial contributions to conception and design, acquisition of data, or analysis and interpretation of data; took part in drafting the article or revising it critically for important intellectual content; agreed to submit to the current journal; gave final approval of the version to be published; and agree to be accountable for all aspects of the work.

\section{Disclosure}

The authors report no conflicts of interest in this work.

\section{References}

1. Arponen H, Mäkitie O, Waltimo-Sirén J. Association between joint hypermobility, scoliosis, and cranial base anomalies in paediatric Osteogenesis imperfecta patients: a retrospective cross-sectional study. BMC Musculoskelet Disord. 2014;15:428. doi:10.1186/14712474-15-428

2. Kang H, Aryal ACS, Marini JC. Osteogenesis imperfecta: new genes reveal novel mechanisms in bone dysplasia. Transl Res. 2017;181:27-48. doi:10.1016/j.trs1.2016.11.005

3. Lim J, Grafe I, Alexander S, Lee B. Genetic causes and mechanisms of osteogenesis imperfecta. Bone. 2017;102:40-49. doi:10.1016/j. bone.2017.02.004

4. Marini JC, Forlino A, Bachinger HP, et al. Osteogeneis imperfect. Nat Rev Dis Primers. 2017;3:17058-17072. doi:10.1038/nrdp.20 17.52

5. Monti E, Mottes M, Fraschini P, et al. Current and emerging treatments for the management of osteogenesis imperfecta. Ther Clin Risk Manag. 2010;6:367-381. doi:10.2147/tcrm.s5932

6. Lindahl K, Langdahl B, Ljunggren Ö, et al. Treatment of osteogenesis imperfecta in adults. Eur $J$ Endocrinol. 2014;71:R79-90. doi:10.1530/EJE-14-0017

7. Lamanna A, Fayers T, Clarke S, et al. Valvular and aortic diseases in osteogenesis imperfecta. Heart Lung Circ. 2013;22:801-810. doi:10.1016/j.hlc.2013.05.640

8. McKiernan FE. Musculoskeletal manifestations of mild osteogenesis imperfecta in the adult. Osteoporos Int. 2005;16:1698-1702. doi:10.1007/s00198-005-1905-5

9. Charnas LR, Marini JC. Communicating hydrocephalus, basilar invagination, and other neurologic features in osteogenesis imperfecta. Neurology. 1993;43:2603-2608. doi:10.1212/WNL.43.12.2603

10. Tsipouras P, Barabas G, Matthews WS. Neurologic correlates of osteogenesis imperfecta. Arch Neuro. 1986;43:150-152. doi:10.10 01/archneur.1986.00520020044016

11. Sasaki-Adams D, Kulkarni A, Rutka J, Dirks P, Taylor M, Drake JM. Neurosurgical implications of osteogenesis imperfecta in children: report of 4 cases. J Neurosurg Ped. 2008;1:229-236. doi:10.3171/ $\mathrm{PED} / 2008 / 1 / 3 / 229$

12. Tauer JT, Robinson ME, Rauch F. Osteogenesis imperfecta: new perspectives from clinical and translational research. JBMR Plus. 2019;3(8):e10174. doi:10.1002/jbm4.10174

13. Biggin A, Munns CF. Osteogenesis imperfecta: diagnosis and treatment. Curr Osteoporos Rep. 2014;12:279-288. doi:10.1007/ s11914-014-0225-0

14. Warman ML, Cormier-Daire V, Hall C, et al. Nosology and classification of genetic skeletal disorders: 2010 revision. Am J Med Gen Part A. 2011;155:943-968. doi:10.1002/ajmg.a.33909

15. Mortier GR, Cohn DH, Cormier-Daire V, et al. Nosology and classification of genetic skeletal disorders: 2019 revision. Am J Med Gen Part A. 2019;179:2393-2419. doi:10.1002/ajmg.a.61366

16. Rauch F, Glorieux FH. Osteogenesis imperfecta. Lancet. 2004;363:1377-1385. doi:10.1016/S0140-6736(04)16051-0

17. Seeliger F, Leeb T, Peters M, et al. Osteogenesis Imperfecta in Two Litters of Dachshunds. Vet Path. 2003;40:530-539. doi:10.1354/ vp. $40-5-530$ 
18. Scott PP, McKusich VA, McKusick AB. The nature of osteogenesis imperfecta in cats: evidence that the disorder is primarily nutritional, not genetic, and therefore not analogous to the disease in man. $J$ Bone Joint Surg. 1963;45:125-134. doi:10.2106/00004623-19634501000010

19. Jensen PT, Rasmussen PG, Basse A. Congenital osteogenesis imperfecta in Charollais cattle. Nordisk Veterinaermedi. 1976;28:304-308.

20. Arthur DG, Thompson KG, Swarbrick P. Lethal osteogenesis imperfecta and skin fragility in newborn New Zealand Romney lambs. NZ Vet J. 1992;40:112-116. doi:10.1080/00480169.1992.35712

21. Horvath SA, Francesetti FL, Riveros SV. Treatment of imperfect osteogenesis in a tiger (Panthera tigris). Avances En Ciencias Veterinarias (Chile). 1986;1:49-51.

22. Campbell BG, Wootton JA, Krook L, DeMarco J, Minor RR. Clinical signs and diagnosis of osteogenesis imperfecta in three dogs. $\mathrm{J} \mathrm{Am}$ Vet Med Assoc. 1997;211:183-187.

23. Lettow E, Dammrich K. Clinic and pathology of osteogenesis imperfecta in young dogs. Zbl Vet Med. 1960;7:936-966.

24. Dehaan JJ, Peck JN, Campbell B, et al. Osteogenesis imperfecta in three dogs from a single litter. Vet Comp Ortho Traum. 2000;13:23-27. doi:10.1055/s-0038-1632625

25. Quist EM, Doan R, Pool RR, et al. Identification of a candidate mutation in the COL1A2 gene of a chow chow with osteogenesis imperfecta. $J$ Heredity. 2017;109:308-314. doi:10.1093/jhered/ esx 074

26. Lindert U, Weis MA, Rai J, et al. Molecular consequences of the SERPINH1/HSP47 mutation in the dachshund natural model of osteogenesis imperfecta. J Biol Chem. 2015;290(29):17679-17689. doi:10.1074/jbc.M115.661025

27. Campbell BG, Wootton JA, Macleod JN, Minor RR. Canine COL1A2 mutation resulting in c-terminal truncation of Pro- $\alpha 2$ (I) and severe osteogenesis imperfecta. J Bone Min Res. 2001;16: 1147-1153. doi:10.1359/jbmr.2001.16.6.1147

28. Letko A, Zdora I, Hitzler V, et al.A de novo in-frame duplication in the COL $1 \mathrm{~A} 2$ gene in a Lagotto Romagnolo dog with osteogenesis imperfecta. Anim Genet. 2019;(50):786-787. doi:10.1111/age.12843

29. Rosset E, Rannou B, Casseleux G, Chalvet-Monfray K, Buff S. Agerelated changes in biochemical and hematologic variables in Borzoi and Beagle puppies from birth to 8 weeks. Vet Clin Pathol. 2012;41:272-282. doi:10.1111/j.1939-165X.2012.00415.x

30. Harper EJ, Hackett RM, Wilkinson J, Heaton PR. Age-related variations in hematologic and plasma biochemical test results in Beagles and Labrador Retrievers. J Am Vet Med Assoc. 2003;223:1436-1442. doi:10.2460/javma.2003.223.1436
31. Brenten T, Morris PJ, Salt C, et al. Age-associated and breed-associated variations in haematological and biochemical variables in young Labrador retriever and miniature schnauzer dogs. Vet Rec Open. 2016;3:e000166. doi:10.1136/vetreco-2015-000166

32. Dammrich K. Osteoporoses in young animals. Pathol Vet. 1967;4:435-463. doi:10.1177/030098586700400502

33. Rowe DW, Shapiro JR. Osteogenesis imperfecta. In: Avioli LV, Krane SM, editors. Metabolic Bone Disease. 3rd ed. London, UK: Academic Press; 1998:651-695.

34. Wilson DA. Angular Limb Deformity. In: Clinical Veterinary Advisor the Horse. St. Louis, Missouri, Estados Unidos: Elsevier/Saunders; 2013:30-31.

35. Engelbert RH, Graaf YV, Empelen RV, et al. Osteogenesis Imperfecta in Childhood: impairment and Disability. Pediatrics. 1997;99 (E3):1-7. doi:10.1542/peds.99.2.e3

36. Veilleux LN, Trejo P, Rauch F. Muscle abnormalities in osteogenesis imperfecta. J Musculoskel Neuro Inter. 2017;17:1-7.

37. Costa PP, Custodio J, Ebina FS, et al. Osteogenesis imperfect in an young pinscher dog. Acta Scientiae Veterinariae. 2018;46 (Supplement).

38. Gold R, Pool RR, Edwards EE. Osteogenesis and dentinogenesis imperfecta in a four-month-old English mastiff. Vet Rec Case Rep. 2019;7(3):e000835. doi:10.1136/vetreccr-2019-000835

39. Aizenbud D, Peled M, Figueroa AA. A combined orthodontic and surgical approach in osteogenesis imperfecta and severe class iii malocclusion: case report. J Oral Maxillofac Surg. 2008;66: 1045-1053. doi:10.1016/j.joms.2008.01.010

40. Marshall C, Lopez J, Crookes L, Pollitt RC, Balasubramanian M. A novel homozygous variant in SERPINH1 associated with a severe, lethal presentation of osteogenesis imperfecta with hydranencephaly. Gene. 2016;95:49-52. doi:10.1016/j.gene.2016.09.035

41. Campbell BG, Wooton JA, MacLeod JN, Minor RR. Sequence of normal canine COL1A1 and identification of a heterozygous alpha1 (I) collagen Gly208Ala nutation in a severe case of osteogenesis impferfecta. Arch Biochem Biophys. 2000;384:37-46. doi:10.1006/ abbi.2000.2099

42. Drogemuller C, Becker D, Brunner A, et al. A missense mutation in the SERPINH1 gene in Dachshunds with osteogenesis imperfecta. PLoS Genet. 2009;5:e1000579. doi:10.1371/journal.pgen.1000579

43. Craig LE, Dittmer KE, Thompson KG. Bone and Joints. In: Maxie MG, editor. Jubb, Kennedy, and Palmer. Pathology of Domestic Animals. 6th ed. Missouri: Elsevier; 2016:157-163.
Veterinary Medicine: Research and Reports is an international, peerreviewed, open access journal publishing original research, case reports, editorials, reviews and commentaries on all areas of veterinary medicine. The manuscript management system is completely online and includes a very quick and fair peer-review system. Visit http://www.dovepress.com/testimonials.php to read real quotes from published authors. 